\title{
Adequacy of DEA in Measuring the Efficiency of Public Sector Entities in Nigeria: A Comparative Analysis Approach
}

\author{
Odewole, Philip Olawale \\ University Hospitals, Nigeria \\ waleodewole@gmail.com
}

\begin{abstract}
The study examined the efficiency of Decision- Making Units (DMUs) in the public sector entities in Nigeria. The study focused on the efficiency in the utilization of personnel cost releases to the federal educational and health institutions by the Federal Government of Nigeria. Secondary data were sourced from the Annual General Warrants from Audited financial statements of the Public Sector entities. Sampled size for the study comprised twenty-five (25) DMUs each from both sectors out of the major Federal Ministries from four (4) geo-political Zones and Abuja. Data were analyzed using Data Envelopment Analysis Model (DEA). The results of the average efficiency scores from both Charnes, Cooper and Rhodes Model (CCR) and Banker, Charnes and Cooper (BCC) on the DMUs showed that the sectors were marginally inefficient. The summary of the overall results therefore revealed that the DMUs under health sector performed averagely better than education sector in the utilization of personnel cost allocations. The study recommended that a central monitoring team be created jointly by the Federal Ministry of Finance and Accountant-General's office to ensure full utilization of personnel cost releases to the DMUs. The study therefore concluded that only continuous assessment and periodic appraisal of the personnel cost utilization by the supervising ministries, can guarantee full efficiency in the utilization of personnel cost releases.
\end{abstract}

Keywords: Efficiency, DMUs, Health Sector, Education Sector, DEA.

\section{Introduction}

Public sector entities are a set of organizations with a mandate to carry out public programs and provide general services for the general welfare of the populace (Kara, 2012). They are the vehicles of central system through which government cardinal ideas reach the masses at the grassroots. A well -functioning public sector entity facilitates effective public financial management. Over the years, the public sector entities in Nigeria witnessed a significant transformation through series of financial reforms carried out in the sector. These reforms were predicated on needs to redress and address the critical issues of loss of confidence on public financial transactions. Generally, public sector entities are categorized according to their reliance on central authority's funding for carrying out their core functions. The first on the list of such category are the public sector entities that are fully funded by central authority. In this category, the central authority is wholly responsible for the provision of adequate funding for all the operating activities of the entities such as personnel cost allocations, capital grants allocations, overhead cost allocations and funding for repairs and maintenance of equipment. The entities are therefore not allowed to keep any part of its own internally generated revenue within its coffers. It is expected that such own internal generated funding be remitted wholly to the federal coffers. Next to this are the entities that are self-funded.

These are public entities that generate own funding to cover all its operating expenses. They are therefore responsible for the payment of staff salaries, payments for capital acquisition and providing funding for repairs and general maintenance. All the Internally Generated Revenue accrued to such entities as inflows are kept within their coffers. The last category is partly funded by the federation account. This group receives major allocations such as personnel cost allocations, capital grant releases and overhead cost allocations for financing day-to-day activities of the enterprise and offsetting staff salaries payments. They are equally allowed to generate own revenue to fill up the shortfalls from the central authority and also remit part of the internally generated revenue to the coffers of the Consolidated Revenue Fund (CRF). Examples of such entities are the Federal Universities, Federal Colleges of Education, Federal Polytechnics, Federal Teaching Hospital, all Federal Medical Centers etc. The focus of this study is on this group of entities which are partly funded by the central authority. The purpose of this study is to investigate the efficiency of utilization of personnel cost allocations by the central authority to the federal institutions in both education and health sector. The focus is to determine which of the entities in both Health and Education are more efficient in the utilization of personnel cost resources under review. 
The paper therefore aims at analyzing the efficiency of utilization of personnel cost allocations by the public sector entities under both education and health sector using DEA models - CCR and BCC. The work provides information to the top echelons in both education and health sectors on the efficiency of utilization of personnel cost releases to the Ministries, Departments and Agencies (MDAs). The remainder of the paper is therefore organized as following. Following the introductory section, section two (2) reviews the literature. Section three (3) presents data and methodology adopted in the study. Section four (4) discusses the results of findings while section five (5) concludes the study with policy recommendations for improving the efficiency of the entities.

\section{Literature Review}

The measurement of the public sector entities' efficiency adopting both parametric and non-parametric frontier models is popular among both the economics and finance researchers. The application of Data Envelopment Analysis (DEA) is prominent among the various approaches in frequent usage. The univariate nature of ratio analysis with major limitation in appraising firms' performance has exposed the strength of DEA in the determination of entities' efficiency (Yu, Barros, Tsac and Liao, 2014). DEA is a linear programming tool used to measure the relative efficiencies of a set of Decision- Making Units (DMUs) in a production process (Yilmaz and Yurdusev, 2011). DEA is a non-parametric method which measures the efficiency of a DMU from a single input and single out efficiency analysis to multi-input and multi-output situation (Abdulkareem \& Oyeniran 2011). It assumes no random mistakes. DEA was proposed by Charnes, Cooper and Rhodes (1978). The efficiency performance measurement backdated to Farrel (1957) who introduced both technical efficiency and allocative efficiency. This technique has been used in many fields of the world ranging from school, hospitals, financial, security, administration (Agasisti \& Johnes, 2009, Kwon \& Lee, 2015, Tao, Liu, \& Chen, 2013, Tsolas and Charles, 2015, Ahn, Charnes \& Cooper, 1988). The main uses of DEA are the evaluation of management and program efficiencies of DMUs of not-for-profit-making organization like schools, hospitals etc (Cyrek, 2017; Stanickova, 2017).

Many scholars have employed DEA window analysis in the assessment of influence on operational efficiencies of the hospitals (Kazley and Ozcan, 2008, Jia and Yuan, 2017). The preference for the use of DEA by many researchers for the determination of entity's efficiency is partly due to its advantage over the traditional ratio because of the simultaneous use of multiple inputs and outputs for the determination of efficiency (Cheng, Cai, Tao, He, Lin \& Zuo 2016, Czypionka, Kraus, Mayer \& Rohrling, 2014). Opinions in the use of DEA and its benefits differ among the scholars. In the case of primary and secondary healthcare service deliveries, inputs data used in the determination of healthcare efficiency are sometimes uniform. In order to achieve improved health promotion within the organization, health outcomes are sometimes increased (Harnandez \& San, 2014, Rezaee \& Karimdadi, 2015, Samut \& Cafri, 2016, Sendek, Svital kova \& Angelovicova, 2015). Therefore, the adoption of DEA is a dominant approach in assessing the efficiency of the healthcare system, educational institutions and other economic units across the globe. Previous studies on efficiency were based on productive efficiency which subsequent authors built upon (Farrel, 1957). Also, the public choice theory and bureaucracy was equally dominantly adopted in various works on efficiency by numerous authors (Tullock, 1965). However, the present study is anchored on the public sector entity's allocative efficiency theory as a theoretical framework to fill the gap created by the caveat.

\section{Methodology}

The study investigated panel data of (50) fifty public sector entities in both the federal educational institutions and federal health institutions in Nigeria. Taro Yamane technique was employed to determine the sample size from the total population of Decision- Making Units (DMUs) in the two sectors. Both Charnes, Cooper and Rhodes (1978) models and Banker, Charnes and Cooper (1978) models were applied for the comparative analysis on the personnel data obtained from the sector in the determination of efficiency of utilization of personnel cost allocations. The study adopted both constant and variable inputs and outputs of Data Envelopment Analysis (DEA) techniques. Out-put oriented model focuses on the capacity of DMUs to achieve the level of output from the limits of available inputs in the entity. The input-oriented model on the other hand, measures the capacity of a DMU to maintain the maximum level of production with the available inputs in the organization. 
The usefulness of DEA has found a deep root in the healthcare sector and the educational institutions. In output-oriented version, the efficiency score for the DMUs ranges from 1 to infinity but in the input -oriented version, efficiency score is between 0 and 1 . The efficiency score is estimated as the ratio of weighted outputs to weighted input (Charnes et al., 1978). Weights are selected from each variable of every analyzed unit in order to maximize its \efficiency score. The efficiency rate for each unit of the reference set of $j=1, \ldots, n$. DMU is evaluated in relation to other set members (Charnes et al., 1978). The maximal efficiency score is 1 , and the lower values indicate the relative inefficiency of the analyzed objects. The DEA model with m inputs variables, s outputs variables, and u DMU's, the envelopment form of the input-oriented model is given by (Charnes et al., 1978) and Cooper et al. (1978) in their proposition as follows: $\operatorname{maxh}_{0}(u, v)=\frac{\sum_{r} u_{r} y_{r 0}}{\sum_{i} v_{i} x_{i 0}}$

Subject to:

$\frac{\sum_{\mathrm{r}} \mathrm{u}_{\mathrm{r}} \mathrm{y}_{\mathrm{r} 0}}{\sum_{\mathrm{i}} \mathrm{v}_{\mathrm{i}} \mathrm{x}_{\mathrm{i}}} \leq 1$ for $\mathrm{j}=1, \ldots, \mathrm{n}$,

$\mathrm{u}_{\mathrm{r}}, \mathrm{v}_{\mathrm{i}} \geq 0$ for all $\mathrm{i}$ and $\mathrm{r}$

The proposition developed by (Charnes and Cooper, 1978) was employed for linear fractional programming. This proposition then selects a combination of solution of $(u, v)$ for which $\left.\sum_{i-1}^{n} v_{i} x_{i 0}=1\right)$ and results into the equivalent linear problem in which the variance of variables from $(u, v)$ to $(\mu, v)$ is a direct result of the application of DEA model as propounded by "Charnes-Copper" transformation which can be re-written as: $\operatorname{maxz}=\sum_{\mathrm{r}-1}^{\mathrm{s}} \mu_{\mathrm{r}} \mathrm{y}_{\mathrm{r} 0}$

Subject to:

$$
\sum_{r-1}^{s} \mu_{r} y_{r j}-\sum_{i-1}^{m} v_{i} x_{i j} \leq 0
$$

$\sum_{i-1}^{m} v_{i} x_{i 0}=1$

$$
u_{r}, v_{i} \geq 0
$$

For which the linear programming dual problem is

Subject to:

$$
\Theta^{*}=\min \Theta
$$

$$
\begin{aligned}
& \sum_{j-1}^{n} x_{i j} \lambda_{j} \leq \Theta x_{i 0} i=1,2, \ldots, m ; \\
& \sum_{j-1}^{n} y_{r j} \lambda_{j} \geq y_{r 0} r=1,2, \ldots, s ;
\end{aligned}
$$

$\lambda_{j} \geq 0 j=1,2, \ldots, n$.

This expressional transformation is the original DEA model and commonly referred to as the "Farell model" by a wide range of finance and economic scholars. It is otherwise referred to as the output-oriented model that aims at maximizing outputs of a given DMU with the given input level at a particular time. The second is the input-oriented model, which also aims at minimizing inputs at a given output level (Cooper et al., 1978): $\min \Theta-\varepsilon\left(\sum_{i=1}^{m} S_{i}^{-}+\sum_{r=1}^{n} S_{r}^{+}\right)$

Subject to:

$$
\begin{aligned}
& \sum_{j=1}^{n} \lambda_{j} x_{i j}+S_{i}^{-} \leq \Theta x_{i 0} i=1,2, \ldots, m ; \\
& \sum_{j=1}^{n} \lambda_{j} y_{r 0}+S_{i}^{+}=y_{i 0} r=1,2, \ldots, s ; \\
& \lambda_{j} \geq 0 j=1,2, \ldots, n \\
& \sum_{j=1}^{n} \lambda_{j}=1
\end{aligned}
$$

Where, $x i j$ indicates the ith input of the $j$ th DMU, $y_{r j}$ indicates the $r$ th output of the $j$ th DMU, and $\lambda j$ and $u_{r}$, indicate the weight of the $j$ th DMU while $v_{r}$ is the efficiency score of $D M U_{\mathrm{j} .}$. If the constraint $\sum_{\mathrm{j}=1}^{\mathrm{n}} \lambda_{\mathrm{j}}=1$ is adjoined, they are then referred to as the Banker, Cooper and Charmes model (BCC model) (Banker et al., 1988). The BCC model is also otherwise referred to as the Variables Return to Scale (VRS). The VRS assumption is different from the CCR assumption which is referred to as the Constant Returns to Scale (CRS model). The VRS assumption or BCC model considers the variation of efficiency with respect to the level or scale of operation and measures pure technical efficiency arising from the variables. The BCC model or the VRS assumption is used to measure the scale efficiency which is determined as follows:

Scale Efficiency $=\frac{\text { Technical efficiency from CRS }}{\text { technical officiency from VRS }}$

The determination of adequate model variables (inputs and outputs) was the second important consideration used in measuring efficiency of the public entities. Also, Cooper et al. (1978) and Paradi, David and Fai (2018) 
indicate that the number of DMUs should be at least three times the total number of inputs plus outputs used in the models. Cook, Kaoru and Joe (2014) suggested a similar rule in order to set a minimum number of DMUs in relation to the number of variable inputs to have a meaningful result with a clear set of efficient and inefficient units which are expressed as follows:

$\mathrm{n} \geq \max \{\mathrm{m} \times \mathrm{s}, 3(\mathrm{~m}+\mathrm{s})\}$,

Where $\mathrm{m}, \mathrm{s}$, and $\mathrm{n}$ are the numbers of inputs, outputs and DMU's respectively.

\section{Interpretation of Results}

Table 1 showed the average efficiency scores in personnel costs for the 25 sampled DMUs in the federal health institutions using CCR model. The mean efficiency scores for DMUs in the utilization of the personnel cost allocations are between 0.317 and 0.969.This implies that none of the DMUs attained a full efficiency of $100 \%$ or 1 . That is, none of the DMUs among the federal health institutions fully utilized all the personnel cost releases to the various DMUs during the period. Rather, most of them held on to the idle personnel cost balances which were either unspent, diverted or locked up in private personal accounts. With the efficiency score of 0.317 in the sector, it shows that the personnel cost resource usage was unimpressive. It shows that some of the DMUs had sticky personnel cost balances left idle during the financial year. It also means that the personnel cost allocations to the DMUs were in excess of their actual needs. The DMUs were therefore inefficient in the personnel cost resource utilization during the research periods. A DMU is fully efficient in the utilization of resources when its efficiency scores is $100 \%$ or 1 . That means there is a full utilization of resource usage in the entity. However, if the efficiency score is less than 1, then the DMU is either marginally inefficient, distinctively inefficient or averagely inefficient. The implication of inefficiency in the personnel, cost usage with the DMUs is that there is more surplus personnel cost allocation available within the DMUs than the actual need of the personnel staff.

Table 1: The Average Efficiency Scores Distribution across the Selected DMUs in the Health Sector using the CCR Approach

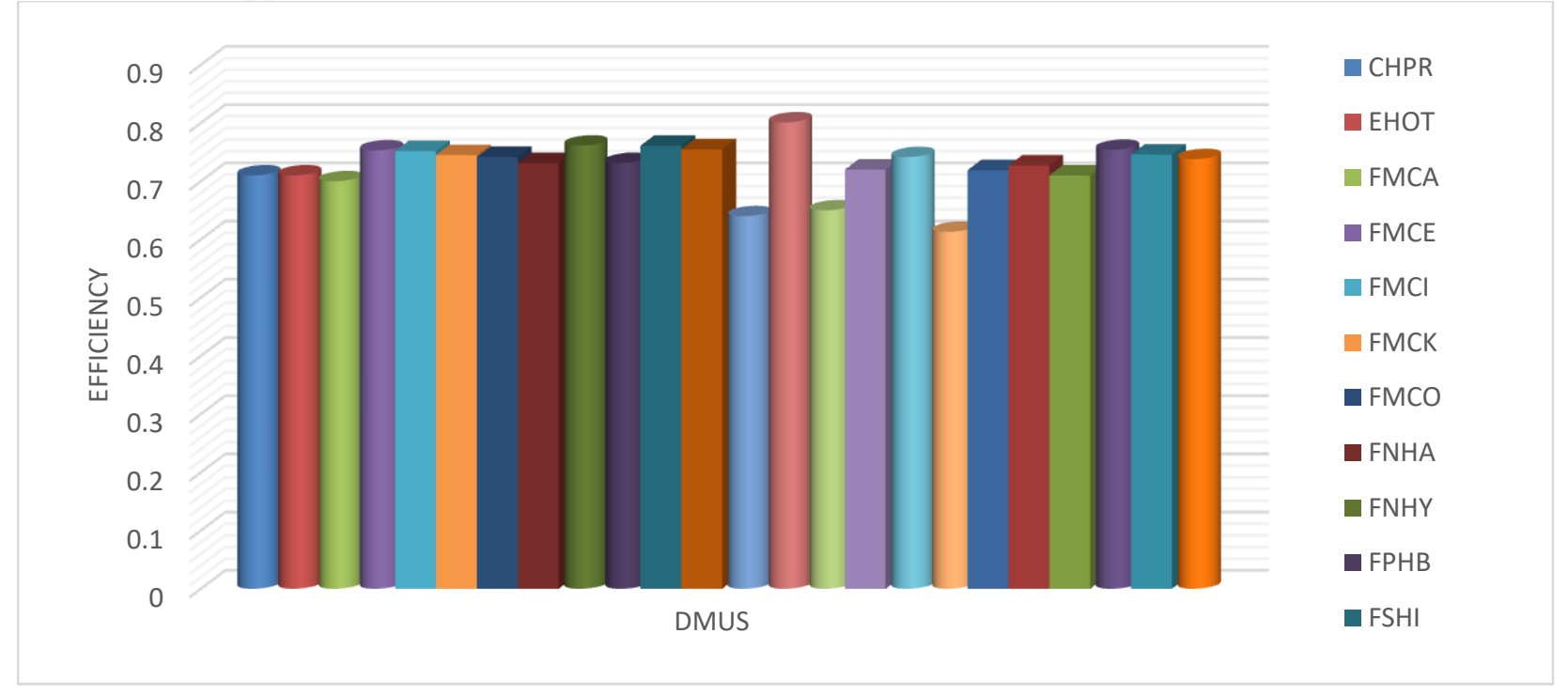

Table 1 shows the average efficiency scores distribution across the selected DMUs in the health sector using the CCR approach. The table shows a fair performance among the DMUs. Figure 1 shows the ranking of the pool of average efficiency score weights attached to the use of personnel cost among the DMUs in health sector. DMUs capabilities in the efficient usage of personnel cost in the health sector ranges between 60 and $80 \%$. This is suggestive of a fair performance in the way personnel costs were utilized in the health sector. The average efficiency scores show that the DMUs were marginally inefficient in personnel cost resource usage. Among the sampled DMUs, MLSCY recorded the highest average efficiency score among the twentyfive DMUs. This implies that the highest rate of personnel cost utilization or absorption was recorded by MLSCY, while NTPA was the last on the ranking list. The implication therefore is that NTPA has surplus 
personnel cost balances that were neither utilized by the DMU nor returned to the central treasury as expected at the end of each year for the use of other DMUs with insufficient balances.

Figure 1: Ranking of Average Efficiency Scores in Personnel Costs Utilization in the Sampled DMUs in Health Sector using CCR

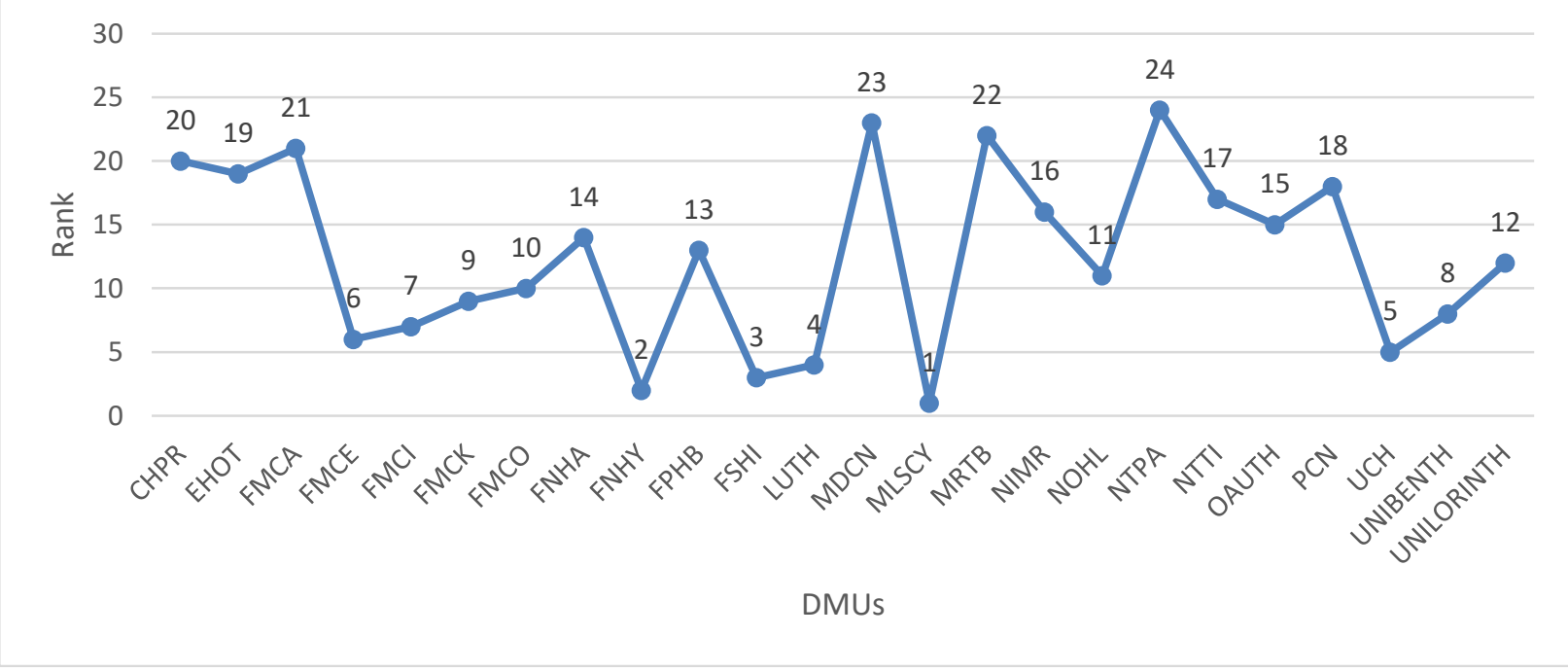

Figure 1 shows the ranking of average efficiency scores in personnel costs utilization for the Sampled DMUs in health Sector Using CCR. The summary of the ranking shows a reasonable performance among the DMUs. Table 2 shows the summary of analysis results for the average efficiency scores in personnel costs utilization among the sampled DMUs in health sector using BCC model. From the table, average efficiency scores for the DMUs ranges from 0.672-0.955 signifying a better average efficiency scores distribution for the DMUs under BCC model. However, none of the DMUs attained a full average efficiency score of $100 \%$ whereby the personnel cost releases to the DMUs were fully utilized in the payment of staff salaries during the research period. However, the pattern and trend of average efficiency scores show an impressive usage of personnel cost utilization among the DMUs. The efficiency scores distribution pattern with the application of BCC in the sector is slightly better than the efficiency scores performance under CCR. The impression therefore is that the DMUs under health sector are marginally inefficient in the personnel cost resource usage.

Table 2: The Average Efficiency Scores Distribution across the Selected DMUs in the Health Sector using the BBC Approach

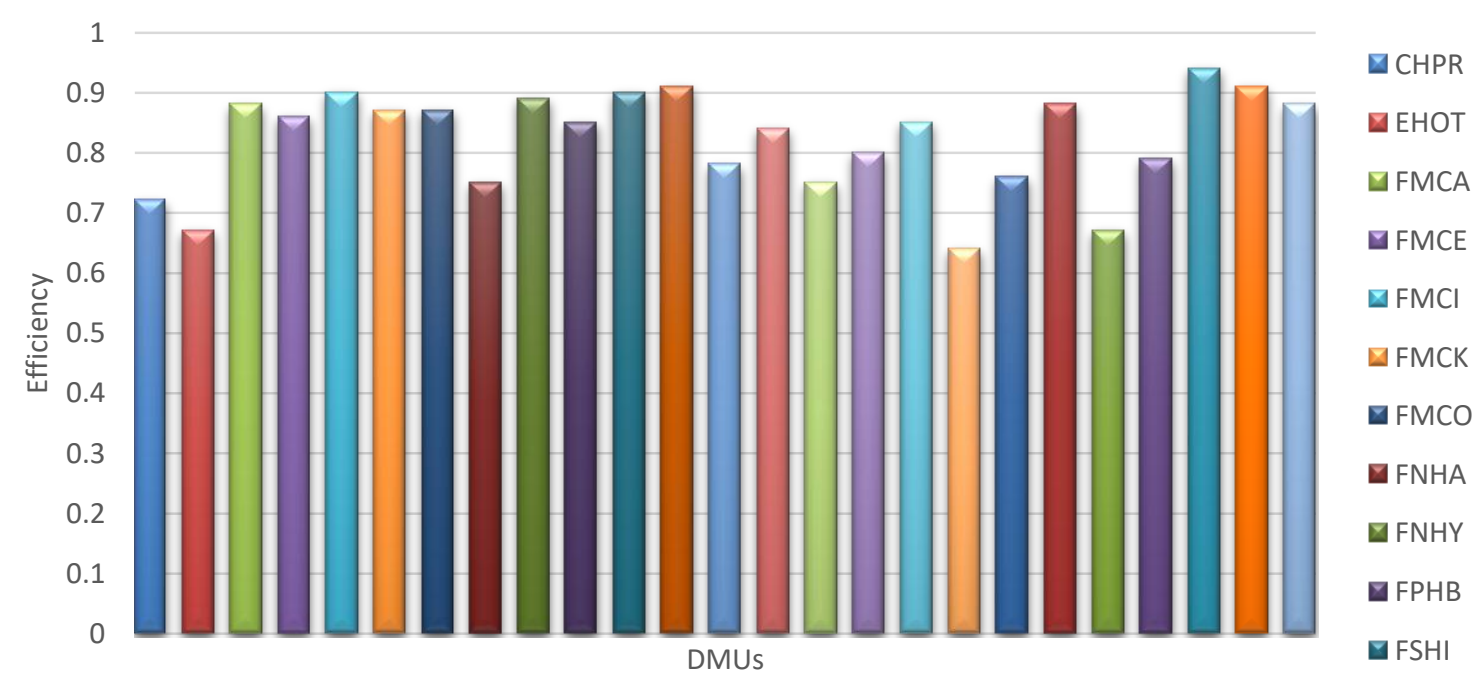


Table 2 shows the average efficiency scores distribution across the selected DMUs in the health sector using the BCC approach. The table shows a good performance in the utilization of personnel cost releases to the DMUs. Figure 2 shows the ranking of average efficiency scores on personnel cost usage among the sampled DMUs in the health sector using BCC model. UCH is on top of the list of the average efficiency ranking with the highest average efficiency score in the overall class of scores of 94\%. NTPA, however, comes last in the efficiency ranking with the lowest average performance of average efficiency scores of $64 \%$. The average efficiency scores performance of other DMUs were stated between the high and low of average efficiency scores performance.

Figure 2: Ranking of Average Efficiency Scores in Personnel Costs Utilization for the Sampled DMUs in Health Sector using BCC Model

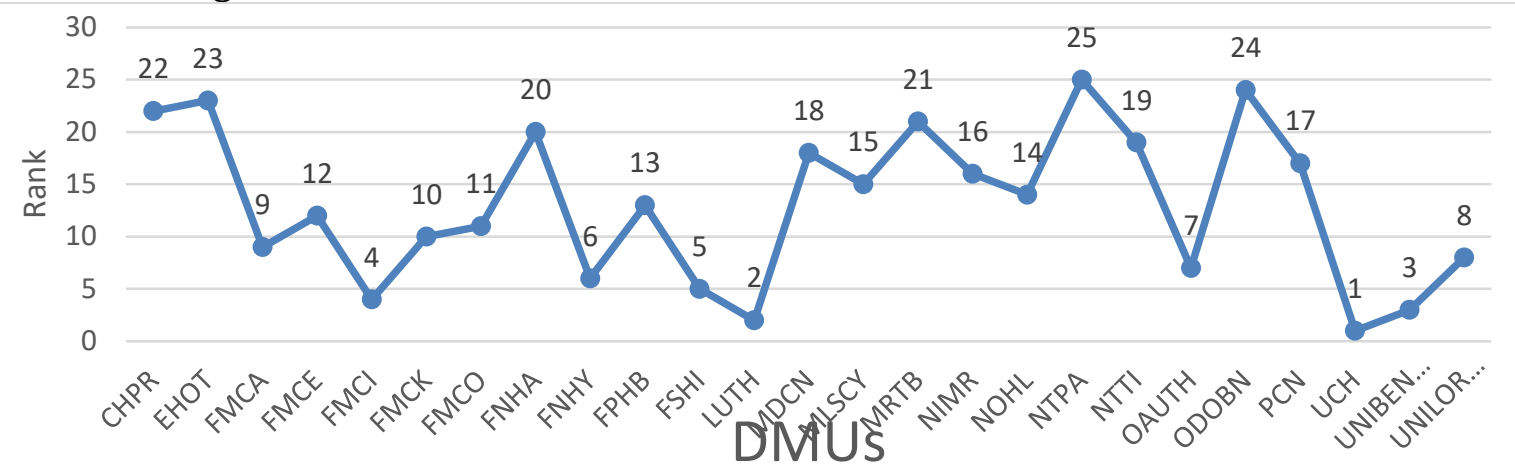

Figure 2 shows the ranking of average efficiency scores in personnel costs usage for the sampled DMUs in health sector using BCC model. UCH ranked first on the list while NTPA came last of the ladder. Table 3 presents the summary of the analysis of the distribution of average efficiency scores in the utilization of personnel costs among the DMUs in Education sector using CCR model. The spread of the average efficiency scores on the utilization of personnel cost allocation in the education sector was unimpressive. Most of the DMUs in the sector were averagely inefficient with the average efficiency scores of $65 \%$. The implication is that most of the DMUs in the sector did not efficiently maximize the personnel cost resource made available to fund the payment of staff salaries. Personnel cost allocations to the DMUs were far in excess of the actual needs of the entities. Therefore, the sticky personnel cost balances at the end of the year in the DMUs were as a result of inefficiency in the utilization of personnel cost resource.

Table 3: The Average Efficiency Scores Distribution for Personnel Cost Utilization across the Selected DMUs in the Education Sector using the CCR

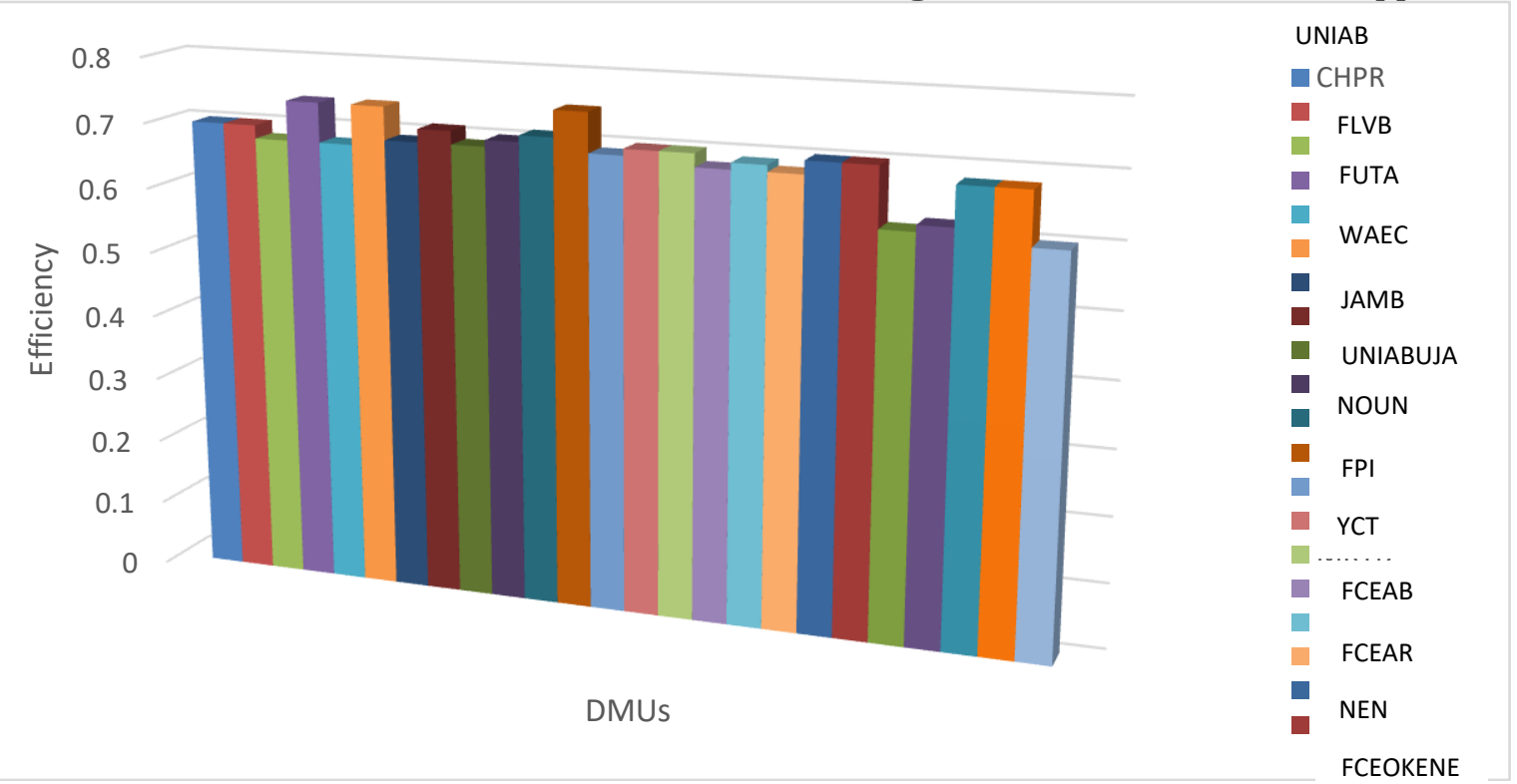


The table shows the average efficiency scores distribution across the selected DMUs in the education on the utilization of personnel cost allocations. Figure3 shows the average efficiency scores ranking on the utilization of personnel cost allocation for the DMUs in the education sector. Average efficiency scores are steady across the DMUs except in the case of UI which shows a peak in the average efficiency scores. UI had the highest average efficiency score in the overall class of scores with $75 \%$ while UNIAB recorded the lowest average performance of $60 \%$. The summary of the average efficiency scores performance for the DMUs under the sector is comparatively low in reference to the performance under the health sector. The inference therefore is that DMUs under the health sector are more efficient in the usage of personnel cost allocations than the counterparts in education sector.

Figure 3: The Ranking of Average Efficiency Scores in Personnel Costs Utilization for the Sampled DMUs in Education Sector using CCR Model

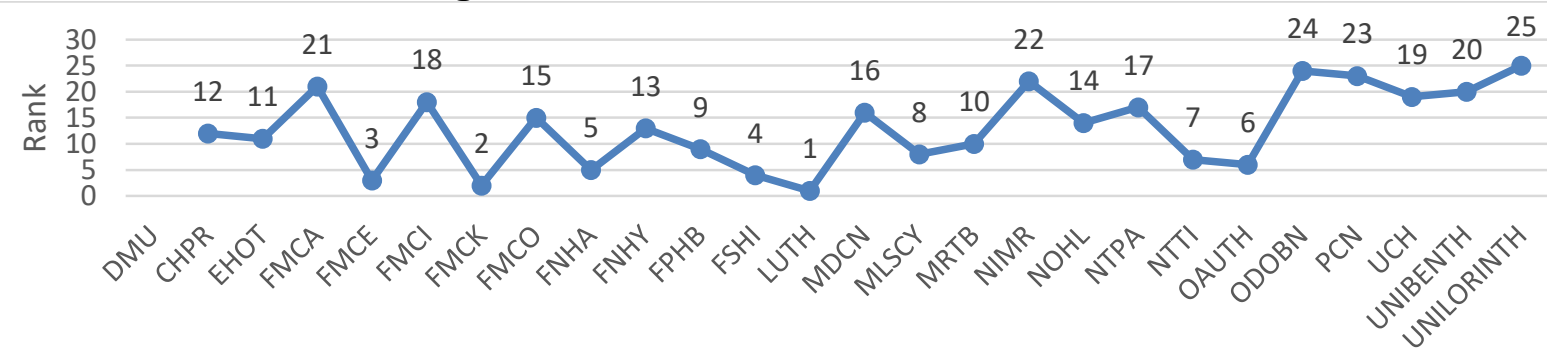

DMUs

Figure 3 shows the average efficiency scores ranking in Personnel Costs utilization among the sampled DMUs in Education sector using CCR model. Table 4 presents the summary of analysis of results for the average efficiency scores in personnel costs usage for the sampled DMUs in Education Sector using BCC model. On the average, the personnel costs utilization among the DMUs in the education sector was not as impressive as in health sector. Most of them retain idle personnel cost balances which were released to them over and above the normal requirements. Unfortunately, the unused sticky fund is either ploughed back to the personnel account with DMUs or returned to the central treasury for fair distribution among the DMUs.

Table 4: The Average Efficiency Scores for Personnel Cost Utilization across the Selected DMUs in the Education Sector using the BCC Approach

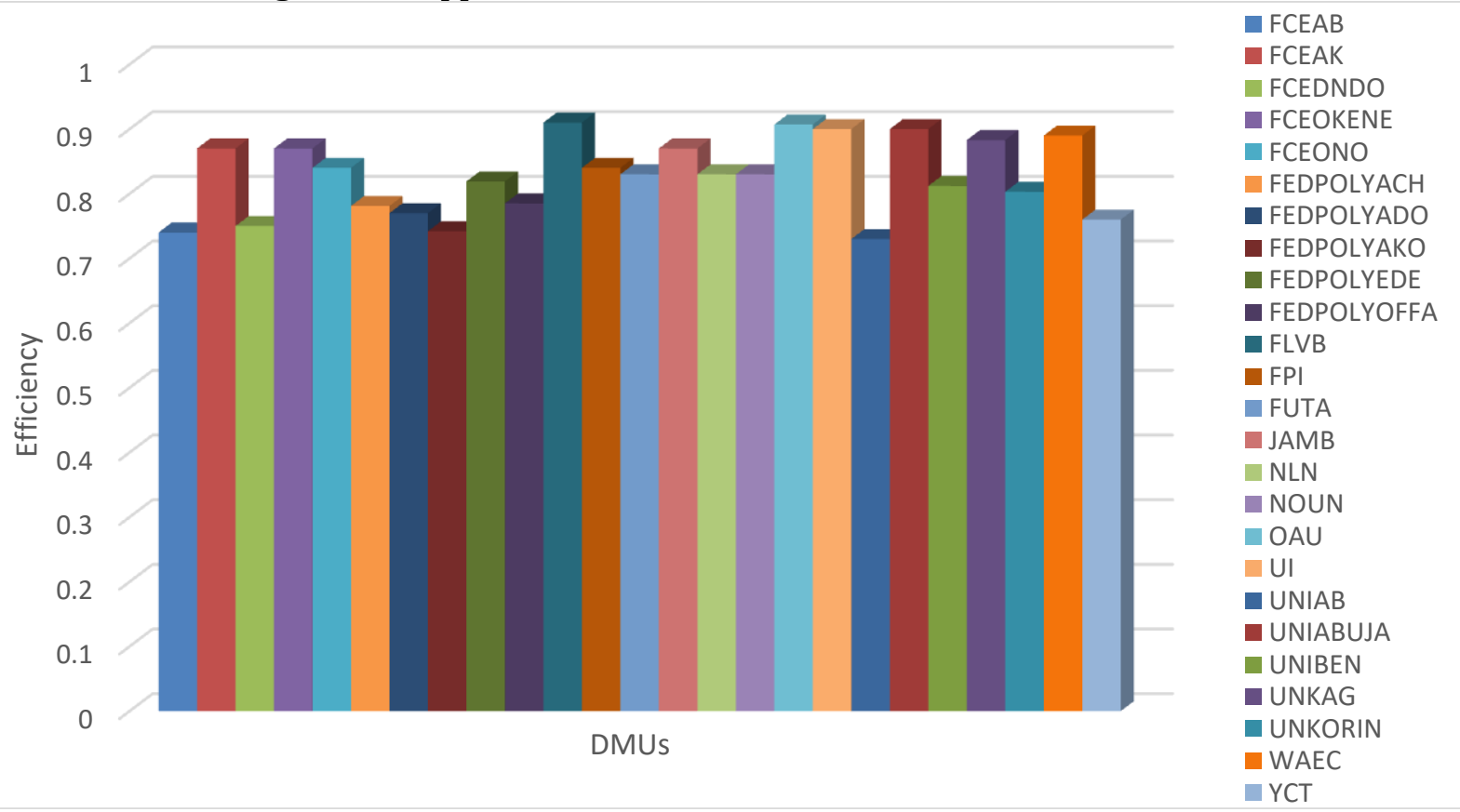


The table shows the average efficiency score distribution for personnel cost utilization across the selected DMUs in the education sector using the BCC approach. Figure 4 shows the ranking and the pattern of behavior of pool of average efficiency weight attached to the use of personnel cost among the DMUs in Education sector. DMUs capacity ranges between $70 \%$ and $91 \%$ in the efficient usage of personnel cost in the sector. There is a steady efficiency score performance across the DMUs except in the case of FLVB which shows a spike to the peak in the overall class of scores. From the ranking chart, FLVB and OAU have the highest average efficiency scores ranking in the overall class of scores with $91 \%$ while UNIAB recorded the lowest average efficiency scores performance of $73 \%$. The application of BCC in the determination of efficiency scores in the sector shows that there is an impressive performance among the entities in the utilization of personnel cost usage.

The spread of the average efficiency scores among the DMUs reveal the ability of the entities under education to utilize the personnel cost resource. The evaluation of the DMUs efficiency under the sector was better with the application of BCC than other the health sector. The range of 73\%-91\% efficiency scores performance show that the entities effectively maximized the personnel cost resource allocated to the DMUs with little slack balances. However, the deviation between performance range and full efficiency of $100 \%$ show that the DMUs did not fully utilize the personnel cost allocations to the entities. It shows that personnel cost estimates were over and above the actual personnel cost fund needed to finance staff salary expenditure in the entities. The sticky balances also indicate that some of the DMUs either kept idle personnel cost balances or diverted the surplus fund to other purposes instead of paying it back to the central treasury.

Figure 4: Ranking of Average Efficiency Scores in Personnel Costs for the Sampled DMUs in Education Sector using BCC Model

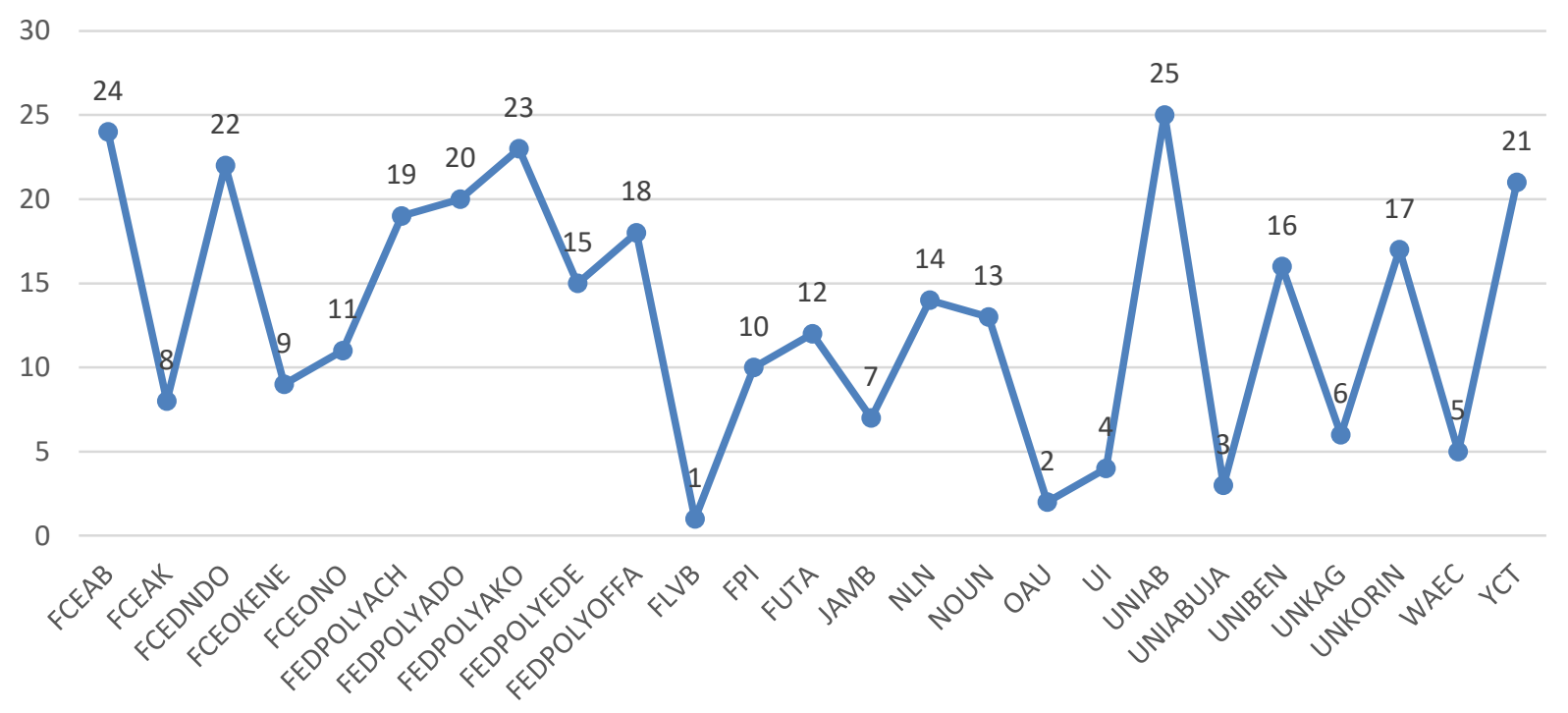

Figure 4 shows the ranking of DMUs based on their average efficiency scores in personnel costs usage for the sampled DMUs in Education Sector using BCC model.

\section{Conclusion and Recommendations}

The study evaluated the efficiency of the DMUs under both health and education sector in the utilization of personnel cost releases using DEA techniques. Both CCR and BCC models were adopted for the comparative analysis results of the DMUs. The results from both techniques showed that none of the DMUs under the two sectors were technically efficient in the utilization of personnel cost releases during the research period. However, results of the findings on the utilization of personnel cost allocations show that DMUs under health sector performed averagely better than DMUs under education with application of both CCR and BBC techniques. The implication is that DMUs under health maximized effectively the personnel cost releases for the payment of staff salary better than their counterparts under education. 
The unspent personnel cost balances under education sector show that the sector is averagely efficient in the utilization of personnel cost resource. It is also an indication that the personnel cost releases to the DMUs in the sector were over and above the actual needs of the entities. The spread of average efficiency scores among the DMUs in the health sector are less marginally efficient and more skewed to full efficiency frontiers signifying an improved utilization of personnel cost allocations in the sector. The paper therefore concluded that only central authority's control, supervising ministries' effective monitoring of the personnel cost releases to the DMUs and the periodic appraisal of the personnel cost utilization by the Budget office of the federation in conjunction with the office of the Accountant-General of the federation can guarantee an improved efficiency performance and enhance optimum utilization of personnel cost allocations among the DMUs in the sectors.

Policy Recommendations: In order to enhance the DMUs' efficiency performance in the two sectors, the following recommendations must be in place: The budget office of the federation should set up the monitoring team to regulate the activities of all DMUs in the two sectors in terms of the personnel cost utilization vis-à-vis the size of the institutions' payroll. Henceforth, personnel cost allocations to the DMUs should be based on the degree of need as against political scheming which is presently the order of the day. Also, the central authority should make mopping up exercise on monthly basis whereby unspent personnel costs balances are mopped up and redirected to the areas of need among the DMUs. The supervising authorities of both health and education sector should enforce strict rules so that all DMUs will either adjust their personnel cost inputs or increase the size of the payroll to achieve full efficiency in line with personnel cost releases.

They should regulate the appointment processes in all DMUs in proportion to their personnel cost budget. All efforts should be on deck by the central authority to discourage the DMUs holding idle personnel cost balances as unspent from their personnel cost releases. All the chief executive officers should be made answerable to the available sticky personnel cost balances in the various accounts of the DMUs and proper investigation should be carried out on the judicious utilization of the personnel cost resource and any culprits should be brought to books. Appropriate financial appraisal techniques should be adopted in order to carry out the need assessment of the DMUs in both health and education sector to enhance accountability and efficiency. DMUs' budget estimates should be properly scrutinized before central authority approval. Personnel cost budget implementation's appraisal should be carried out on quarterly basis to confirm compliance with personnel cost appropriate disbursement.

\section{References}

Abdulkareem, A. Y. \& Oyeniran, S. (2011). Managing the performance of Nigeria universities for suitable development using data envelopment analysis. International Journal of Academic Research in Business and Social Science, 15(1), $54-67$.

Agasisti, T. \& Johnes, G. (2009). Comparing the efficiency of higher education decision making units across more than one country. Education Economics, 17, 59 -79.

Ahn, T., Charnes, A. \& Cooper W. (1988). Some statistical and DEA evaluations of relative efficiencies of public and private institutions of higher learning. Socio-economic Planning sciences, 22(6), 259 -269.

Charnes, A., Cooper, W. W. \& Rhodes, E. (1978). Measuring the efficiency of decision- making units. European Journal of Operation Research, 2(2), $429-444$.

Cheng, Z., Cai, M., Tao, H., He, Z., Lin, X., Lin, H. \& Zuo, Y. (2016). Efficiency and productivity measurement of rural township hospitals in China: a bootstrapping data envelopment analysis. BMJ Open, 6(11), 1 11.

Cyrek, M. (2017). Social efficiency of employment in three sectors - a comparison of Polish regions. Quarterly Journal of Economics and Economic Policy, 12(3), $417-432$.

Czypionka, T., Kraus, M., Mayer, S. \& Rohrling, G. (2014). Efficiency, ownership and financing of hospitals. European Journal of Operation Research, 5(3), 9 -24.

Farrel, M. J. (1957). The measurement of productive efficiency. Journal of royal statistical society, 120(3), 253 -270 .

Harnandez, A. R. \& San, S. M. (2014). Assessing the technical efficiency of health posts in rural Guatemala: A data envelopment analysis. Global Health Action, 2(1), 1- 12. 


\section{Journal of Economics and Behavioral Studies (ISSN: 2220-6140)}

Vol. 12, No. 5, pp. 13-22, October 2020

Jia, T. \& Yuan, H. (2017). The application of DEA (data envelopment analysis) window analysis in the assessment of influence on operational efficiencies after the establishment of branched hospitals. BMC Health Service Research, 17(1), 265 - 289.

Kara, E. (2012). Financial analysis in public sector accounting. An example of EU, Greece and Turkey. European Journal of Science Researches, 6(1), 81-89.

Kazley, A. S. \& Ozcan, Y. A. (2008). Electronic medical record use and efficiency. A DEA and windows analysis of hospitals. Socio Econ. Plan Sci, 43(3), 209 - 221.

Kwon, H. B. \& Lee, J. (2015). Two-stage production modeling of large U. S. Banks: A DEA-neural network approach. Expert Systematic Application, 42, 6758 -6766.

Rezaee, M. J. \& Karimdadei, A. (2015). Do geographical locations affect hospital performance? A multi-group data envelopment analysis. Journal of medical system, 39(9), 1- 11.

Samut, P. K. \& Cafri, R. (2016). Analysis of the efficiency determinant of health systems in OECD countries by DEA and panel. Tobit Social indicators Research, 2(1), 1- 20.

Sendek, S. \& Svitalkova, K. (2015). Efficiency evaluation of hospitals in environment of the Czech and Slovak Republic. Acta Universities, 63(6), 2109 - 2118.

Stanickova, M. (2017). Can the implementation of the Europe 2020 strategy goals be efficient? The challenge for achieving social equality in the European Union. Equilibrium Quarterly Journal of Economics and Economic Policy, 12(3), 383 - 398.

Tao, L., Liu, X. \& Chen, Y. (2013). Online banking performance evaluation using data envelopment analysis and axiomatic fuzzy set clustering. Qualitative and quantitative Journal, 47, 1259- 1273.

Tsolas, I. E. \& Charles, V. (2015). Incorporating risk into bank efficiency: A satisficing DEA approach to access the Greek banking crisis. Expert System Application Journal, 42, 3491 - 3500.

Tullock, G. (1965). The Politics of bureaucracy. First edition. Michigan: Public Affairs Press.

Yu, Y., Barros, A., Tsai, C. \& Liao, K. H. (2014). A comparison of ratio and data envelopment analysis: Efficiency assessment of Taiwan public listed companies. International Journal of Academic Research in Accounting, Finance and Management Sciences, 4(1), 212 - 219.

Yilmaz, B. \& Yurdusev, M. A. (2011). Use of data envelopment analysis as a multi criteria decision tool - A case of irrigation management. Mathematical and computational Application, 16(3), 669 -679. 